\title{
At the Crossroads of Science and Society: Careers in Science Policy
}

\author{
Amy P. Patterson, ${ }^{1}$ Mary E. Groesch, ${ }^{1}$ Allan C. Shipp, ${ }^{1}$ and Christopher J. Viggiani ${ }^{2}$ \\ ${ }^{1}$ Office of the Director, National Heart, Lung, and Blood Institute, National Institutes of Health, Bethesda, \\ Maryland 20892 \\ ${ }^{2}$ Office of University Compliance, Oregon State University, Corvallis, Oregon 97331 \\ Correspondence: amy.patterson@nih.gov
}

Science policy offers a challenging and rewarding career path for scientists interested in the social, ethical, and legal implications of their field. This topic encompasses a broad spectrum of activities all in support of advancing the scientific enterprise. Science policy spans various sectors, and policy careers are found in many different organizations, including the federal government, scientific societies, and professional organizations. Although their specific duties may vary greatly, science policy professionals generally apply their scientific training to ensure that the scientific enterprise advances in a responsible and ethical manner and to solve challenges with broad scientific and societal implications.

Cience policy is an area of public policy con$S$ cerned with the course and conduct of the scientific enterprise. A thriving scientific enterprise is a vital national priority that is intertwined with broader national interests such as economic competitiveness, public health, environmental health, energy production and consumption, education, food production and safety, international relations, and national security. Science directly and indirectly impacts almost every area of life and, as such, developing science policy requires an ongoing dialog among scientists, policy makers, and the public. It is this realm, at the center of the dialog between science and society, where policy professionals work to shape the policies that advance the scientific enterprise in a manner that is ethical and acceptable to society as a whole. This chapter describes science policy careers as they pertain to the life sciences, with a focus on those in biomedical research. We primarily discuss careers in the U.S. government but will touch on policy careers in other sectors.

In the biomedical context, science policy is aimed at advancing basic and applied research to address public health priorities. Advancing biomedical research and developing new disease treatments are essential, but doing so in a responsible, ethical manner is equally important. Striking this balance can be challenging, given how rapidly many life sciences disciplines are advancing. But as scientific frontiers advance and discoveries and technologies push the boundaries of what is possible, new questions with scientific, ethical, legal, social, and political dimensions emerge and must be addressed.

For instance, the National Institutes of Health deals with a broad range of constantly

Editors: Kaaren Janssen and Richard Seve

Additional Perspectives on Career Options for Biomedical Scientists available at www.cshperspectives.org

Copyright (C) 2018 Cold Spring Harbor Laboratory Press; all rights reserved; doi: 10.1101/cshperspect.a032854

Cite this article as Cold Spring Harb Perspect Biol 2018;10:a032854 
A.P. Patterson et al.

evolving policy issues. Some current areas of focus include policies related to clinical research, genomic data sharing and oversight, biosafety, biosecurity, emerging biotechnologies, and the return on public investment in research. In seeking to advance the life sciences in a manner that is responsive to both public health needs and any ethical or other concerns associated with the science, we grapple with a host of challenging questions. For example, how can the privacy of human subjects involved in clinical or genomic research be protected? When published, could some of the information from research on dangerous pathogens provide a blueprint for bioterrorists? How should ethical concerns surrounding embryonic stem cell research be addressed? What are the risks associated with emerging fields, such as synthetic biology or nanotechnology? What potential burden will a new policy place on the research community? Is that burden acceptable? Answers to these types of questions are embodied in the policy responses that guide how research is conducted, technologies are pursued, and treatments are developed.

The policy process begins with the identification of a problem or issue. Then, policy makers begin to develop policy options or recommendations. In doing so, they consult with the public, subject matter experts, and other stakeholders to determine how best to address the issue. Stakeholders for a given issue might include scientists, medical and public health professionals, research institutions and hospitals, pharmaceutical and biotech industries, patients, the scientific publishing community, the public at large, and many more. Ultimately, policy makers decide on and implement a course of action and periodically review the policy to ensure that it adequately addresses the problem and keeps pace with the changing scientific landscape. Science policy professionals fulfill key roles at each step in this process with their leadership, policy analysis, scientific expertise, and advocacy efforts.

There are many areas of science policy, and science policy careers can be found in many sectors. Here, we primarily discuss careers in biomedical science policy, the skills required to succeed in science policy, strategies for mov- ing from the laboratory or clinic into science policy, and different policy career paths. Regardless of the path, the ever-changing and unpredictable nature of scientific progress makes science policy a dynamic and rewarding career choice.

\section{JOBS}

There is no "typical" science policy job. But careers in science policy generally involve "the bigger picture" and offer individuals an opportunity to work at the intersection of science and society. The exact role of a science policy professional varies depending on the mission of their organization and its role in the policy process. Below, we describe science policy in the executive branch of the federal government and note some of the other sectors involved in science policy.

Almost every federal department or agency invests in or has an interest in life sciences research and they therefore use policy professionals to shape their research programs or contribute scientific input to their policy activities. The federal government funds all types of life sciences research, typically through extramural programs (i.e., research conducted by independent scientists supported by federal funds) and intramural programs (i.e., research conducted by government scientists). Basic and applied biomedical research is supported by the U.S. Department of Health and Human Services and its component agencies.

- The National Institutes of Health (NIH) funds and conducts basic and applied life sciences research aimed at enhancing health, lengthening life, and reducing illness and disability.

- The Centers for Disease Control and Prevention (CDC) conducts scientific research and provides health information to protect the public against health threats.

- The Food and Drug Administration (FDA) helps to ensure the safety and effectiveness of various life sciences research products, such as vaccines, drugs, and medical devices. 
Many other federal agencies fund or have a direct interest in life sciences research as well, including the National Science Foundation, Environmental Protection Agency, and the Departments of Energy, Homeland Security, Defense, and Veterans Affairs. The Office of Science and Technology Policy, within the Executive Office of the President, coordinates science-related policy development activities for the executive branch and also provides the President and senior staff with sound scientific and technical advice on policy matters.

Policy professionals at these and other federal agencies coordinate the policy process, analyze or develop policies, and work to implement policies. They may conceptualize or advance a research agenda or initiative or develop policies that help to ensure that the scientific enterprise advances, and new innovations are developed in a safe, responsible manner. Policy professionals also commonly manage working groups or committees of experts who are enlisted to make policy recommendations on a given issue. These activities generally occur at many levels, ranging from the broad (i.e., government-wide policy development and coordination) to the more specific (i.e., policy analysis and development specific to a division, branch, or research area). Science policy professionals commonly review policy documents and consider them according to their impact on the scientific enterprise and their agency's mission. When developing policies, policy professionals routinely organize meetings, workshops, or conferences to solicit important feedback from stakeholders.

Science policy jobs exist outside of the government as well. These jobs vary greatly based on the scope of the organization's work, structure, and role in the policy process. Some of these organizations are federally funded; others are private research institutions (which can be for- or not-for-profit). Typically, these organizations are commissioned by the government to provide objective expert advice and analysis, coordinate studies, or manage projects at the request of a federal department or agency. For instance, the National Academies of Sciences, Engineering, and Medicine regularly issue reports that help to shape policy, inform public opinion, and advance the pursuit of science, engineering, and medicine. Scientific and professional societies also conduct studies on how policies impact their constituents, and many universities have academic centers devoted to the study of specific areas of science policy. $\mathrm{Nu}$ merous other research and development centers-sometimes called think tanks-provide specialized expertise and support.

Other opportunities in science policy are found in scientific societies or professional associations that represent the interests of their scientific communities, institutions, or other stakeholders. These organizations form a conduit between their communities and the federal policy makers. They regularly communicate with their constituents and policy makers, stay abreast of relevant policy issues, and shape policy discussions with their analysis and input. Examples of such organizations include the American Association for the Advancement of Science, the Federation of American Societies for Experimental Biology, the American Society for Microbiology, the Association of Public and Land-Grant Universities, the Association of American Universities, the Association of American Medical Colleges, the Pharmaceutical Research and Manufacturers of America, the Biotechnology Industry Organization, and countless others representing constituents with a stake in the scientific enterprise. Government relations specialists at individual biotech and pharmaceutical companies, as well as universities and medical centers, also routinely interface with policy makers, monitor relevant policy developments, and advocate their entity's position on given policy issues.

Finally, there are policy jobs that are less about developing policies that guide the conduct of scientific research and more about ensuring that science informs policy development. The FDA, for instance, uses scientific information when developing science-based regulatory approaches for new drugs and medical devices. These approaches range from pre-market review of efficacy and safety to post-market product surveillance to review of product quality. The CDC also relies on scientific input in its efforts to detect and monitor existing and 
A.P. Patterson et al.

emerging health threats. This information informs various policy responses, such as determining how much and what types of vaccines should be produced. In addition, there are federal agencies whose primary missions do not involve supporting research activities but nevertheless have an interest in the scientific enterprise or how scientific findings affect and inform their areas of focus (e.g., the State Department). Budgetary issues impact all policy decisions, including those related to science and technology; as such, the Office of Management and Budget employs individuals with scientific expertise. The legislative branch also deals with a host of policy issues, many of which directly involve scientific research, whereas other issues are informed by scientific consensus. Policy professionals working in regulatory science, in "nonscience" agencies, or serving as staff to senators, representatives, or congressional committees may communicate science to policy makers and contribute an understanding of scientific issues related to the development of broader public policy.

\section{SKILLS AND QUALIFICATIONS}

Although few academic degrees are offered in science policy, the skills one acquires by earning an advanced degree in the natural or social sciences, medicine, public or international health, public policy administration, law, ethics, economics, or other related fields are immensely beneficial. In general, an advanced degree, such as a master's degree, $\mathrm{MD}, \mathrm{PhD}$, or JD, is required to get a start in science policy, and such degrees may help individuals to advance as a science policy professional. Generally, but not universally, senior-level life sciences policy professionals have doctoral degrees in a medical or scientific discipline. A master's degree in public health can be valuable for certain positions and other master's degrees can help to get a foot in the door or provide a candidate with a particularly desirable area of expertise. Postdoctoral research experience or additional training is not necessary but may be beneficial if it allows a candidate to strengthen their analytic skills or develop expertise in an area that is particularly desirable to a given policy office or organization.

Strong analytic skills are crucial to succeed in science policy. A policy analyst needs to be able to quickly hone in on the bottom line of a particular issue. What is the underlying challenge or hurdle? What are the implications for the agency or the research community? Analysts need to be able to quickly distill many pages of scientific or policy rhetoric down to the essential key points and come up with a plan or options for addressing the issues. An analyst also needs to be able to recognize common threads among seemingly disparate items.

In science policy, it is absolutely essential to be able to communicate clearly, both orally and in writing. Writing skills are particularly important. One of the biggest challenges in transitioning from bench science to science policy involves the different writing styles required for each field. Scientific writing and science policy writing both require an ability to communicate ideas clearly and precisely, but proficiency in writing scientific papers does not necessarily translate into being an effective writer in the science policy arena. An essential part of communicating in the policy arena is the ability to communicate effectively to nonscientists or experts in other fields about complex science and policy issues. In policy, it is often necessary to focus on the implications of scientific results rather than on the scientific details per se. Shifting focus away from nitty gritty scientific details to a bigger picture can be one of the most challenging aspects of the transition from the bench to science policy.

In addition, science policy sometimes focuses on controversial, sensitive, or polarizing issues (e.g., embryonic stem cell research, animal research, or genetic testing) that can be especially challenging to address if the personal views of a policy professional differ from the organization's position. Policy professionals should generally be comfortable working in support of their organization's mission.

Science policy work can be exciting and challenging, especially when it involves short time frames, uncertainty, change, politics, and bureaucracy. Policy professionals should be 
flexible and able to roll with the punches because they are often required to draft and analyze policy documents or respond to requests in a matter of days-and often, hours. Many times, policy analysts do not immediately see the outcome or end result of their work; often, they are asked to contribute to an ongoing process or meet a tight deadline only to wait on other input or contributions before the process moves forward. As new policy challenges arise, policy professionals are often expected to develop additional expertise that may be outside of the scientific area in which they are trained. This all makes for excitingand unpredictable-work that often requires policy professionals to adapt and rapidly shift gears.

For careers in science policy, the old adage that "no man is an island" holds particularly true. Although an individual may be the lead on developing a report or organizing a workshop, policy analysts always bounce ideas off others and get input from colleagues who test and hone these ideas. This input may come from within the office, the agency or department, elsewhere within the government, and/ or from private sectors. To be successful in science policy, one must be aware of and open to different perspectives.

Further, to be successful in science policy, policy professionals should be service-oriented and comfortable with the fact that they do not make policy by themselves. Rather, they contribute to a large, collaborative policy development process that often involves managing or working within groups and developing consensus. Developing policy is never the activity of a single individual, and the sphere of influence of science policy professionals is typically behind the scenes; federal policies and reports for public dissemination rarely have authors. This can be a bit of a culture shock for students, postdocs, or clinicians who are used to "owning" their research projects and authoring manuscripts. But policy professionals often derive satisfaction in knowing that they advanced their organization's mission or were a substantive participant in the dialog surrounding an important issue.
Finally, policy professionals must value the consultative process. Policy issues evolve over time but rarely disappear or are fully "solved." Policy professionals should be able to "enjoy the conversation" and not always expect discrete, tangible outputs for each project.

Careers in policy are challenging and incredibly interesting and satisfying. Policy professionals are integral participants in truly important discussions and policy efforts; their work helps to advance the scientific enterprise in ways that broadly benefit society.

\section{GETTING A FOOT IN THE DOOR}

Moving from academia, the laboratory, or the clinic into a career in science policy can be challenging, but it is not impossible. Graduate students, postdoctoral fellows, or early-stage clinicians should begin by developing an area of scientific expertise and demonstrating academic success with research publications, presentations, awards, and other accomplishments. Although a strong publication record may be helpful, researchers with a more modest publication history can still be very competitive for science policy jobs because the other skills and qualifications described above are truly important in science policy. Stand-out candidates are those who supplement their scientific achievements with a broader understanding of the social, ethical, legal, or other implications of scientific research.

To demonstrate this broader interest and understanding, one should explore opportunities outside of the laboratory or clinic. This might include becoming active in student organizations; organizing academic events, workshops, or symposia; or pursuing writing opportunities (particularly related to science, technology, or policy) with newspapers, newsletters, or magazines that are published by universities or professional societies. Volunteer experience related to science or broader policy areas-such as experience with nonprofit organizations, technology transfer offices, academic public policy research centers, or any experience interacting with the public to explain scientific issuesmay also be helpful. Teaching experience can 
A.P. Patterson et al.

be leveraged to demonstrate communication skills and an ability to clearly convey complex scientific information. Numerous other activities can help a candidate prepare for a career in science policy; the idea is to explore opportunities and demonstrate leadership, initiative, an ability to work with others to accomplish goals, and importantly, an interest in the broader implications of science.

Toward this end, it is also important to stay abreast of science policy issues and demonstrate some understanding of the policy process. Many scientific journals have sections devoted to scientific news, editorials, and policy perspectives. Professional societies also typically publish newsletters and have sections on their websites devoted to policy issues that impact their research community. It is not expected that a student or postdoc be an expert on science policy, but knowledge of some of the "hot button" issues and a basic understanding of how the government works serve a candidate well.

When seeking a science policy job with the U.S. government, begin the search at USAJOBS (see the end of this article for URLs) for a comprehensive listing of the job vacancies at federal departments and agencies. Many positions require some prior policy experience, but entry-level positions are available. Science policy or policy-related jobs may also be available through contractor positions that can be sought out through other online job-listing services.

Formal science policy fellowships are also an excellent way for candidates to get a foot in the door of government agencies. These fellowships provide training and experience in science policy offices, exposure to different types of science policy work, and opportunities for networking and making contacts. Such fellowships often lead to permanent positions or provide a stepping stone to other opportunities. The Science and Technology Policy Fellowship, sponsored by the American Association for the Advancement of Science, is one of the most well-known science policy fellowship programs. Other programs include the Presidential Management Fellows Program and the Christine Mirzayan Science and Technology Policy Graduate Fellowship Program. Many scientific societies and associations have science policy fellowship programs as well, including fellowships in congressional offices.

It may also be possible to secure a brief internship (full or part time) in a science policy office within the government or a professional society, either through an internship program or on a volunteer basis. Any kind of regular participation in a policy office is an opportunity to demonstrate passion and suitability for the work. Whether an internship can be secured or not, informational interviews with science policy professionals are quite useful. Not only do these interviews provide a sense of what a career in science policy entails, but they are an opportunity to identify other individuals with whom to confer.

Scientific associations, professional societies, nonprofit organizations, private research centers, think tanks, and academic centers are also sources of policy-related jobs. Positions in such organizations provide opportunities to influence the policy process, become steeped in the issues, conduct studies or analyze policy, and make important contacts in the policy arena.

\section{CAREER PROGRESSION}

Because science policy includes a broad spectrum of activities, policy domains, and sectors, careers can be quite fluid and rarely will any two science policy careers follow the same trajectory. Furthermore, the precise hierarchy of an office or organization involved in science policy varies significantly. In general, however, a career in policy progresses from analytic or technical responsibilities to positions of leadership and management. Typical policy offices might have junior analysts, senior analysts, senior advisors, program directors, and an office director who may be in a senior leadership position for their agency or organization.

Analysts typically monitor policy developments and provide policy options to their leadership. They typically work in teams to prepare reports, issue briefs, option papers, slide presentations, talking points, memos, meeting summaries, fact sheets, and FAQs. They may also help to organize meetings or workshops aimed 
at exploring issues and gathering stakeholder input. More senior analysts are likely to lead individual projects and may have the responsibility of managing or coordinating the efforts of others. As policy analysts gain experience, they often become subject matter experts on particular research or policy areas and may be asked to represent their agency on a particular issue.

Senior advisors or program directors have even more supervisory responsibility and oversee the operation of larger programs or portfolios. These senior policy professionals anticipate emerging policy issues, set priorities for their program, develop a plan for achieving desired goals, and coordinate the efforts of policy analysts and others to achieve those goals. These individuals lead major policy development or other efforts and manage projects. Senior advisors and program directors are typically counted on to provide their organization's leadership with policy analysis and advice about issues that are particularly challenging and perhaps controversial.

A director of an office involved in science policy is in charge of leading and managing all of the policy efforts of their office, branch, division, and/or organization. This involves working with an organization's leadership, federal partners, and other stakeholders to identify policy needs and set priorities. A director of a science policy office makes policy decisions and provides leadership, sometimes at the national level, on key policy issues. Ultimately, a director mobilizes an office and allocates resources to accomplish tasks in support of their office's mission. An office director sets the short- and long-term goals for their office and responds quickly to emerging policy issues.

As with any career, advancement in science policy is based on how well individuals perform their duties. Generally, individuals who advance in science policy careers are those who demonstrate a keen grasp of complex issues, take direction, welcome new challenges, and work well with others. Individuals who effectively analyze and draft policy documents, manage larger projects, help coordinate the efforts of a team, or effectively represent their organization at meetings are often assigned more responsibility, which can lead to career advances. Networking is also important to advancing in science policy and is an excellent way to find new opportunities within federal agencies or other organizations or sectors. Developing strong relationships with colleagues often opens the door to new, sometimes unexpected, opportunities.

There are many ways for science policy professionals to advance their careers. In the government, for example, one can move within or among federal agencies to gain experience in new policy areas, interact with new industries and sectors, and take on leadership responsibilities. Career advancement in science policy can also occur through moves among the public, private, or nonprofit sectors. For example, at the NIH, one may work on a policy issue that has international dimensions that may translate well to a policy position promoting global health at another federal agency or a private foundation focused on international development. As a general rule, individuals should advance their policy careers by seeking out new challenges and responsibilities while continuing to pursue their passions.

\section{CAREER TRANSITIONS}

Although opportunities in science policy exist elsewhere, policy careers are concentrated in the Washington, D.C. area, because analyzing, developing, and implementing science policy occurs largely within, and in association with, the federal government. For this reason, science policy is not one of the most "portable" careers. However, the skills and experiences gained in the policy arena are applicable to other areas, and because science policy professionals interact with stakeholders in many sectors, they can often develop a diverse network of colleagues "outside the beltway."

Private sector positions in government relations or regulatory affairs may be a natural transition for some. For instance, an individual with experience working in regulatory policy at the FDA, or fostering public-private partnerships at the NIH, may be well suited for a career with a biotech or pharmaceutical company. Nonprof- 
A.P. Patterson et al.

\section{BOX 1. Our Experience}

The authors of this chapter all entered science policy through different paths.

\section{Amy's Story}

My career in science and science policy took several unexpected turns. After completing medical school, a residency in internal medicine, and a postdoctoral research fellowship in endocrinology and metabolism, I was on my way to pursue an academic career pathway. However, "life" intervened, and in order to take care of an ill family member in the Washington D.C. area, I postponed my plans to pursue an academic career and worked as a medical officer at the FDA. Instead of being the temporary position that I anticipated, my tenure at the FDA lasted five years. My work in the Center for Biologics Evaluation and Research introduced me to the world of drug development, policy, and regulation. I learned first-hand about product development, clinical trial design, and public health. I was also selected to represent the U.S. Department of Health and Human Services at a World Health Organization meeting on an emerging and controversial area of research, and together with scientists and ethicists representing more than 30 other nations, I helped to develop international guidelines that are still in place today.

My experiences at the FDA opened my eyes to the critical role of policy development and the importance and diversity of global vantage points and profoundly influenced my career path toward science policy. I realized that a career in science policy offered ample opportunity for problem solving and public service while delving into the crossroads of science, ethics, law, and society. I knew that this was the career path for me.

After five years at the FDA, I accepted a position as the Director of the Office of Biotechnology Activities (OBA) within the NIH Office of Science Policy (OSP). OBA analyzed, developed, and implemented policies to address ethical, legal, and social concerns associated with basic and clinical research involving recombinant DNA, genetic technologies, and other emerging biotechnologies. After several years, I took on an even broader range of issues as the Associate Director for Science Policy and the Director of OSP. OSP provides leadership on science policy issues of significance to the $\mathrm{NIH}$, the medical research community, and the public, with particular focus on cross-cutting issues.

\section{Mary's Story}

During my postdoc in a cell biology laboratory, I became increasingly aware that I did not want to stay at the bench and have my whole world revolve around the role of one protein in one step of a subcellular process, nor did I want to teach or work in industry. Instead, I wanted the focus of my career to be "the bigger picture." It was also important that what I worked on could truly have the potential to make a difference in science at a level beyond the bench.

At that time-we are talking more than 20 years ago-science policy was not a very visible nor wellrecognized career option. After considerable exploration, I finally learned about science policy and the AAAS fellowship and was told by many that this was the only way to break into the policy arena. I applied for the fellowship with great excitement, absolutely sure that this was my destiny and unable to imagine a future without that fellowship. But, as you might guess. . .I was not selected for the program!

I did not give up, but continued to pursue every possible lead and contact, and eventually was put in touch with the Director of the science policy unit within the Office of the Director at the NIH. She was looking for someone with a strong scientific background (there were very few scientists in science policy at that time) and was willing to teach that person about policy. Something I said to her in my first interview caught her attention - that it is important to be able to explain even the most complex science in an understandable way to members of the public. I was hired, and one of my favorite tasks for the next several years was writing about the NIH's most important scientific advances for members of Congress and the public - to explain the return on the public's investment in biomedical research.

Although I was crushed at not getting the science policy fellowship, I actually ended up getting a job in science policy a year or two sooner than I would have through the fellowship. My lesson: Do not give up pursuing your passion if you encounter a roadblock - there is always another way forward! 


\section{Allan's Story}

As an undergraduate, I majored in biology at a time when molecular biology was an emerging and exciting field with tremendous promise. I planned on applying to $\mathrm{PhD}$ programs in molecular biology but first wanted some practical laboratory experience to test whether a life as a scientist was right for me. After working for a biotechnology company for a year and a half, I realized that my interest in molecular biology, and science in general, was related to its impact on society more than to the conduct of science itself.

At the time, I was unaware of any formal degree programs in science policy, and so I investigated health policy and health-care management programs. I entered a program in health administration and upon graduation with a master's degree, I worked for a managed care company as a health economics analyst. Quickly, the scope of the job seemed quite small relative to my broader interests, and I subsequently found a position as a policy analyst in the biomedical research division of the Association of American Medical Colleges-an association representing medical schools, teaching hospitals, and academic and scientific societies. There, I worked on a broad array of issues, including the regulation of biotechnology, clinical research ethics, training the research workforce, the use of animals in research, and scientific integrity. The work was stimulating and capitalized on my skills at analysis and writing. After 13 years, though, it was not enough to simply write and think about the issues; I really wished to be working in an environment closer to the science and at the front lines of policymaking. I was fortunate to find a job in the science policy office at the NIH, where I focused on working with the research community about biosafety, biosecurity, and other research matters, and I am also able to stay steeped in policy analysis and development as well—a perfect fit!

\section{Chris's Story}

I have taken a somewhat roundabout career path. I entered science policy as an AAAS Science and Technology Policy Fellow at the NIH after completing a PhD in molecular biology. Throughout graduate school, I was an observer of national politics and became interested in how policy can drive scientific research and innovation. I was drawn to the idea of strengthening our national research portfolio through policy. With the encouragement of an understanding mentor (who himself had dabbled in policy), I became involved in student government, took on other student leadership roles in our department, and took a course in biobusiness. These experiences were essential to making me a competitive candidate for the policy fellowship.

After the policy fellowship, I realized that I had some more research left in my system, so I returned to the bench for a postdoc position with the intent of pursuing the academic track. My postdoctoral work on telomeres was interesting and exciting and my colleagues were incredible, but I soon began to miss the broader "big picture" issues that I had worked on as a policy fellow. Again with the guidance and understanding from a wonderful advisor, I returned to policy, joining the NIH Office of Science Policy to work on biosecurity issues. I became the director of the NIH biosafety and biosecurity program and focused on issues related to global health, lab safety and security, and emerging technologies.

Then, I sought to return to a university to work more closely with those who carry out research and implement federal-level policies. Currently, I am the director for university policy and standards at Oregon State University. I manage a university-wide policy process and work on policies in many areas including academic affairs, student life, research, business and finance, governance and administration, human resources, risk management, and information technology. It has been interesting to work on policy from different perspectives-both as a policy professional in the government who helped develop federal-level science policies and, now, as a university policymaker who develops policies, procedures, and systems to implement and comply with federal policies.

My advice is to work hard at the bench, but be sure to explore opportunities outside the laboratory. Seek out new experiences and responsibilities. Build new skills and know that your experience will translate into different arenas. 
A.P. Patterson et al.

\section{BOX 2. Ten Dos and Don'ts}

1. Do pursue your passion.

2. Do welcome challenges and enjoy problem solving.

3. Do be open to new and unanticipated opportunities, even if it takes you off the career trajectory you had originally planned to be on.

4. Do knock on doors; they usually do not open unless you do so.

5. Do build a network of contacts.

6. Do take a writing course if you are unaccustomed to nonscientific writing.

7. Do aim your efforts at excellence and shift your focus beyond yourself.

8. Do practice patience, negotiation, resiliency, conflict resolution, and time management.

9. Do familiarize yourself with science policy issues and the activities of the agency/organization in which you are interested.

10. Do not forget to stay energized and committed to personal and professional growth.

its, private foundations, and universities also employ government relations professionals.

Universities or other research institutes may be another logical transition for individuals with experience in science policy. Universities often sponsor research programs or other initiatives with specified goals that may require grant specialists, program managers, technology transfer professionals, compliance officers, and individuals with experience in public relations and communicating science to a broader audience. These careers may be a good fit for some individuals with experience in science policy.

\section{WWW RESOURCES}

http://sites.nationalacademics.org/pga/ policyfellows/ Christine Mirzayan Science and Technology Policy Graduate Fellowship Program.

www.usajobs.gov USA Jobs Working for America, U.S. Office of Personnel Management website.

http://www.aaas.org/program/science-technologypolicy-fellowships AAAS Science and Technology Policy Fellowships.

http://www.osp.od.nih.gov/ National Institutes of Health Office of Science Policy.

http://www.phds.org/jobs/nonacademic-careers/ internships-and-careers-in-science-policy Internships and Careers in Science Policy

http://www.pmf.gov/ Presidential Management Fellows Program. 


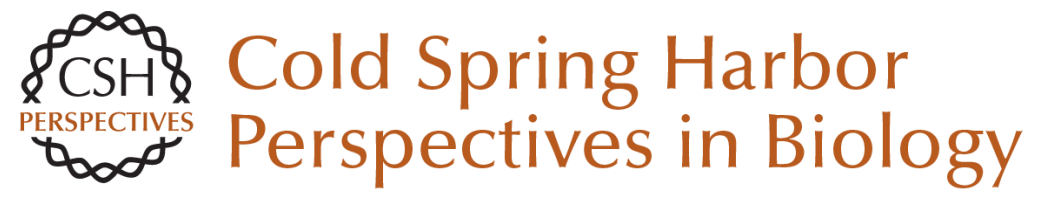

\section{At the Crossroads of Science and Society: Careers in Science Policy}

Amy P. Patterson, Mary E. Groesch, Allan C. Shipp and Christopher J. Viggiani

Cold Spring Harb Perspect Biol 2018; doi: 10.1101/cshperspect.a032854

Subject Collection Career Options for Biomedical Scientists

\section{Careers in Science Publishing} John R. Inglis

Medical Communications: The "Write" Career

Path for You? Yfke Hager

At the Crossroads of Science and Society: Careers in Science Policy Amy P. Patterson, Mary E. Groesch, Allan C. Shipp, et al.

A Career in Patent Law: At the Cutting Edge of Science, but Not at the Bench Salim Mamajiwalla

Careers in Science and Grant Administration: View from the National Institutes of Health Marion Zatz and Sherry Dupere

Careers at Biotech Start-Ups and in

Entrepreneurship Susan Froshauer

Careers in Science Journalism and Writing Helen Pearson

\author{
Careers in Academic Administration \\ Lydia Villa-Komaroff \\ Working for a Scientific Society \\ Martin Frank
A Career for Life Scientists in Management Consulting Rodney W. Zemmel \\ Careers in Core Facility Management \\ Claire M. Brown \\ Leaving the Bench and Finding Your Foundation \\ John E. Spiro
A Career at a Small Liberal Arts College Jennifer Punt \\ Career Options for Scientists \\ Richard Sever and Kaaren Janssen
}

For additional articles in this collection, see http://cshperspectives.cshlp.org/cgi/collection/

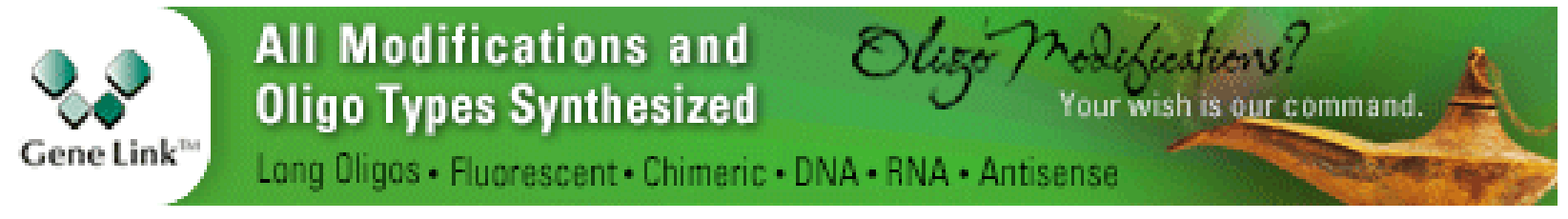

